\title{
Suicide and the Role of Media
}

\section{Sujit Sarkhel}

Associate Professor of Psychiatry, Institute of Psychiatry, Kolkata

(Delivered at CEZIPS 2018, held at Bodh Gaya)

\section{INTRODUCTION}

Media plays a significant role in today's society by providing a very wide range of information in a variety of ways. Various media strongly influence community attitudes, beliefs and behaviour. The factors contributing to suicide and its prevention are complex and not fully understood, but there is evidence that the media plays a significant role. On the one hand, vulnerable individuals may be influenced to engage in imitative behaviours by reports of suicide, particularly if the coverage is extensive, prominent, sensationalist. On the other hand, responsible reporting may serve to educate the public about suicide, and may encourage those at risk of suicide to seek help. Restriction of access to means of suicide and "influencing" media reporting of suicide in the positive direction are two most accepted methods of suicide prevention.

\section{SUICIDE CONTAGION}

The earliest evidence of the impact of the media on suicidal behavior dates back to 1774. In Goethe's book The Sorrows of Young Werther, the hero shot himself because he fell in love with a woman who was beyond his reach. This led to a series of suicides, which occurred across Europe following its release. Many of those who died were dressed in a similar fashion to Werther, adopted his method or were found with a copy of the book.

\section{CONTAGION AND RELATED TERMS}

Imitation is the process by which one suicide exerts a modeling effect on subsequent suicides. Clusters are a number of suicides that occur in close temporal and/or geographical proximity, with or without any direct link. Contagion is the process by which a given suicide facilitates the occurrence of a further suicide. Werther Effect or Copycat Suicides are related terms.

\section{PUBLISHED EVIDENCE}

Philips article in 1974 was the first major research article on Copycat Suicides. He did a retrospective study on increase in suicides following media reporting of suicide. He found a significant increase in the number of suicides in the months in which a front-page suicide report was published. Several subsequent studies from various regions and systematic reviews have strengthened the evidence in favor of imitative suicides.

\section{CHARACTERISTICS OF IMITATION}

There are certain features, which are common to suicides that occur as a result of imitation. Copycat suicides :

- Usually peak within the first three days and level off by about two weeks

- Follows a "dose-response" relationship. i.e., repeated coverage of "high-impact" stories exert maximum effect

- Effects are enhanced when the reader "identifies" with the victim described

- Young adults and elderly individuals are more vulnerable to the effects of imitation

Overt description of a particular method of suicide may lead to imitative acts employing the same method. For example, there was an increase in 
suicides by "burning charcoal" in Britain. Moreover, celebrity suicides may lead to copycat suicides. Marilyn Monroe's reported "suicide" lead to $12 \%$ increase in suicides (303 additional deaths). Suicide by actor Robin Williams in 2014 by hanging lead to $12.8 \%$ increase in suicides in general and $25 \%$ increase in suicides by hanging. The methods were also copied in this case.

\section{IS THE ASSOCIATION SPURIOUS?}

Some authorities argue that those who carry out copycat suicides would have committed the act sooner or later. However, longitudinal studies have revealed that there is no "subsequent decrease" in incidents of suicide after initial increase following copycat suicides. Hence, the "increase" in incidence of imitative suicides is genuine rather than an outcome of a chance association.

\section{WHAT IS PAPAGENO EFFECT?}

Papageno was the protagonist in Mozart's famous opera-the Magic Flute. He becomes suicidal on fearing the loss of his beloved Papageno but three boys teach him alternatives to dying which ultimately prevents him from committing suicide. Papageno effect refers to the protective role that can be played by the media regarding suicide. Etzersd orfer et.al. (1992) reported that after changing the quality of media reporting, the subway suicides in Vienna city decreased significantly. Many subsequent studies have reported similar findings.

\section{MEDIA GUIDELINES ABOUT SUICIDE REPORTING}

\section{Educate the Public about Suicide}

- One should not attribute a suicide to an individual event like exam failure or relationship breakdown

- Causes of suicide are mostly multifactorial

- Suicide should not be depicted as a means of coping with personal problems
- Suicide is often the outcome of underlying mental illness

- Reports exploring these domains will further serve to educate the public about true nature of suicide

2. Avoid language which sensationalizes Suicide

- Avoid the word "suicide" in the headlines

- Avoid sensational terms like "suicide epidemic", simply "increasing rates of suicide" should be enough

- Terms like "unsuccessful suicide" should be avoided-it gives an impression as if suicide was a desired outcome

- "Completed suicide" should be used in preference to "committed suicide"

3. Avoid prominent placement and undue repetition

- Newspaper stories about suicide should ideally be located on the inside pages, towards the bottom of the page

- Undue repetition of stories about suicide should be avoided

- Similarly, broadcast stories about suicide should be presented in the second or third break of television news

- Prominent placement and repetition-both increase chances of imitation

\section{Avoid explicit description of method}

- Step-by-step description may prompt vulnerable people to copy the act

- For example, in reporting an overdose, it would be unwise to detail the nature, quantity or combination of drugs taken,

- This caution should be particularly exercised when the method of suicide is unusual

5. Avoid providing detailed information of location and site

- Detailed description of location or site should be strictly avoided during suicide reporting 
- This often leads to certain places becoming "suicide points" which provokes vulnerable individuals to "plan" suicides keeping these spots in minds

- Numerous such examples of bridges, high rises becoming "media-promoted" favored suicide hotspots

\section{Use photographs or video footages cautiously}

- Photographs or video footage of the scene of a given suicide should not be used

- This may also make the location or method clear to the reader or viewer

- Pictures of an individual who has died by suicide should not be used

- Suicide notes should not be published

\section{Special care in reporting celebrity suicides}

- The community reveres celebrities. Hence, their suicides have strong chances of leading to imitation.

- First of all, speculating about "possible suicide" in the absence of any conclusive report should be strictly avoided

- Avoid detailing

- Reports should not glamourize suicide

- Reports should comment on its impact on others

\section{Other important points}

- Show due consideration for people bereaved by suicide

- Provide information about where to seek help

- Highlight alternatives to suicide

- Publicize risk indicators and warning signs.
- Recognize that media professionals themselves may be affected by stories about suicide

- Always quote reliable sources of information

\section{INTERNET AND THE SOCIAL MEDIA}

Several internet sites provide detailed guidance on methods of suicide, facilitate suicide pacts, offer explicit accounts of celebrity suicides, and/ or display graphic images of people who have died from suicide. Live suicides in "Facebook Live" have been reported in recent times. However, there are no separate guidelines yet for these platforms.

\section{CAN INDIA ACHIEVE THE GOAL OF IMPLEMENTING MEDIA GUIDELINES ON SUICIDE REPORTING?}

India is yet to achieve success in implementing media guidelines on suicide reporting. Efforts from mental health professionals and NGOs are very positive and encouraging in this regard. Dr Lakshmi Vijaya Kumar, one of the stalwarts in the areas of suicide prevention, has prepared guidelines for suicide reporting. While collaboration with media houses is ongoing, a joint meeting of all stakeholders presided by the Ministry of Health and Family Welfare is yet to take place. Certain newspapers have made it mandatory to include suicide helpline numbers in suicide reporting. It remains to be seen how long it takes for media guidelines to be implemented so that it ultimately leads to proper suicide reporting. 